estäo implementando algum processo de reengenharia. Quando se deseja assumir um posicionamento conceitual sobre as formas ou estratégias de ação para aplicaçôes da reengenharia, durante a leitura, nota-se a falta de uma esquematização das diferentes técnicas e possiveis atuaçôs. Para tal esquematizaçấo sobre as abordagens da reengenharia, e oportuno o artigo Reengenharia: um guia de referência para o executioo, de Josê Enesto Lima Gonçalves, publicado na RAE - Revista de Administração de Empresas, São Paulo, v. 34, n. 4, p. 23-30, jul./ago.1994.

Ao indagar o que é reengenharia, os autores apontam alguns dos mitos e realidades a ela associados com freqüûncia, jâ que, para eles, a atual disseminação de conceitos, ter mos ou definiçōes em torno da reengenharia levanta muitas controvérsias. Assim, contestam a noção de que a prătica da reengenharia significa pressupor que antes tudo estava sendo feito errado. Abordam-se também questós como: rengenharia e o uso da tecnologia da informação? Reengenharia significa fazer mais com menos? Ela pode ser usada para resolver um problema? Pode ser gerenciada por qualquer um? Corresponde à verdade a idéia, ou mito, de que a reengenharia é fonte geradora de medo e de ansiedade? E os autores discordam, ainda, da noçào de que a reengenharia $\mathrm{e}$ um processo científico.

Discutem, assim, o que năo é reengenharia e o que ela deveria ser. Para os autores, a reengenharia está associada com a "reinvenção" da empresa, uma prática que impulsiona a posição competitiva da empresa, dá valor aos seus acionistas e contribuiçōes à sociedade. Reconhecem, contudo, as muitas dificuldades para se conseguir implementar essa "reinvenção", e afirmam que para supera-las é necessária uma permanente orientaçẫo para a transformaçảo da organizaçăo.

Algumas atividades importantes, segundo os atores, caracterizam a reengenharia: inovaçä̌; dar ouvido aos consumidores; aprendizagem; geraçăo de idélas; desenho de novos paradigmas; antecipar-se aos concorrentes; contribuir para a melhoria da qualidade do local de trabalho; ponderar as implicaçốes sociais.

Olivro de Bennis e Mische apresenta conceitos extremamente ligados a uma postura executiva que, ao validar os processos de mudança, visa a um futuro de sucesso. A dimensão dos parâmetros por eles propostos supera a visão tradicionalista que ainda se encontra no mundo dos executivos. Ao mostrar uma nova maneira de visualizar a competição, os autores questionam alguns dos velhos paradigmas comportamentais: "Nâo sou melhor do que os outros, sou importante. Eu näo estou separado, sou parte de uma comunidade. Os outros não são meus inimigos, eles são meu benchmarking",

Se pensarmos no caso brasileiro, os autores podem nos sugerir que as empresas precisam vencer os desafios decorrentes dos problemas ligados à necessidade da reduçäo dos custos operacionais e à melhoria da qualidade e dos serviços, se quiserem obter resultados satisfatórios. É também papel relevante a adoção de medidas conciliatórias entre uso de tecnologia e desemprego, reduçầo de niveis hierárquicos e eficiência dos serviços prestados, os progra- mas de qualidade e os custos decorrentes das falhas, com resultados năo-esperados. O desafio continua sendo a prática da aprendizagem.

Na conclusăo, os autores, oportumamente, aconselham os executivos: "Dara aqueles que participam da reengenharia: a reinvençäo oferecentos como que a oportumidade de olhar num espelho, explorar o que se descobriu ecrescer. Numa andise final, a reengenharia de uma organizaçäo deve iniciar com uma reengenharia a partir de você mesmo".

\section{A ÉTICA NA POLÍTICA: VENTURAS E DESVENTURAS BRASILEIRAS}

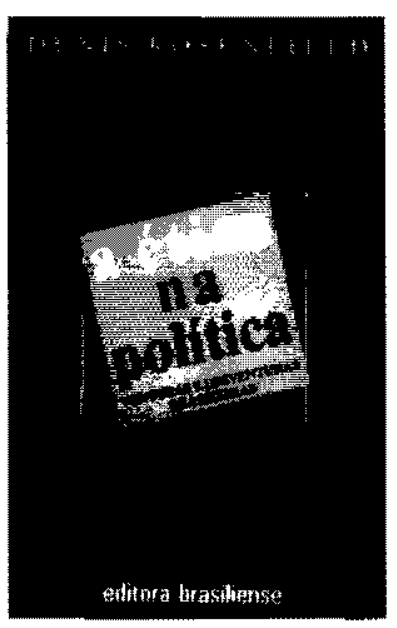

\section{de DENIS ROSENFIELD}

Săo Paulo: Brasiliense, 1992, 90 p.

por Marla Cecilia Coutinho de Arruda, Professora do Departamento de Mercadologia e Coordenadora do CENE (Centro de Estudos de Ética nos Negócios) da EAESP/FGV.

D enis Rosenfield tinha 41 anos quando escreveu este livro. Antes, vivera quatro anos no México e seis na França. Doutorou-se pela Universidade de Paris I Panthéon-Sorbonne, e atualmente é professor do Departamento de Filosofia da Universidade Federal do Rio Grande do Sul e pesquisador do CNPq. Do seu histórico constam ainda várias publicaçôes sobre filosofia política. A sua produçäo junta-se agora $A$ ética na polttica: venturas e desventuras brasileiras, uma obra que faz transparecer a preocupação humanística do autor. 
A primeira versão de alguns capítulos deste livro já foi publicada no jornal Folha de S. Paulo. Nele, o autor $\mathrm{faz}_{f}$ de maneira crítica, um histórico do processo político-eleitoral desde o Plano Cruzado e a mobilização dos "fiscais do Sarney", até o período Collor de Mello. Discutindo com propriedade o que vem a ser a "coisa pública", tẫo talada e tấo pouco respeitada no ambiente político, Rosenfield critica as formas ditatoriais que impedem o exercício da cidadania, lesam direitos humanos e dificultam a formação de uma comunidade politica madura que caracterize verdadeiramente uma naçâo. Ressalta, por isso, a necessidade de o eleitorado saber resistir às coerçoes do aparelho de Estado, bem como manifestar-se contra os vultosos recursos postos à disposição de alguns partidos.

Do ponto de vista socioeconômico, é lembrado que na "transição democráticáa" do Brasil, a inflação galopante terminou por produzir um dilaceramento do tecido social, produzindo, entre outros efeitos; $\circ$ aumento da criminalidade, a perda de confiança na instituição pública e o desregramento da própria vida cotidiana.

Objetivando construir a "coisa pública", Rosenfield argumenta que a sociedade brasileira encontra-se "bloqueada" por uma busca ávida, desenfreada, de exclusiva satisfação de grupos que se movem por interesses cartoriais. Assim, o impasse dessa situação no país é bem mais estrutural do que a crise econômica. A proposta do autor é que se crie uma instância política mediadora dos diferentes interesses em jogo, e capaz de romper os laços arraigados nesse sistema.

Ao analisar a democracia como instituição que detém forte idéia reguladora das relações humanas enquanto livres, o autor remonta ao tempo dos gregos e recolhe a contribuição valiosa de Aristóteles, que já pensava a "repúbli$\mathrm{ca}^{\prime \prime}$ (politela) como o melhor regime político, pelo fato de privilegiar simultaneamente a virtude, a vontade da maioria e as regras que realçam e desenvolvem as determinaçöes racionais e políticas do homem.

Discorrendo sobre o pouco respeito às regras democráticas no Brasil, Rosenfield estabelece um paralelismo com a situaçãa da democracia no Leste Europeu. A derrocada de tantos países dessa regiăo e a própria implosão da União Soviética constituem, para ele, o resultado de um processo histórico em cujo começo apresentou-se, como uma possibilidade concreta, a questão da "redençăo da humanidade pela luta politica". O enfrentamento político é visto como uma açầ que acaba pondo o poder nas mãos de quem garantir melhor regime político. A democracia, em sentido moderno, e definida pelo autor como o resultado de um processo histórico em que o homem apareceu como ser livre, portador de direitos.

E apenas no terceiro capítulo que Rosenfield concretiza sua preocupaçăo especifica com a ética e a política. Na sua opiniāo, a questäo ética no Brasil torna-se séria à medida que a corrupção se alastra, e a reaçăo da sociedade a tal grau de desmoralizaçăo das relaçóes sociais e políticas ainda ê restrita. A existência de măximas do tipo "bateu, levou $^{\prime \prime}$ " 6 dando que se recebe ${ }^{n z}$, rouba, mas faz", desestruturadoras do bem público, podem exigir soluçỏes que levariam o "coletivo" a impor-se por obra de uns poucos que, apropriando-se do aparelho estatal, fariam valer a necessidade de soluçốes emergenciais - única maneira, conforme estes, de se realizar o interesse coletivo.

Rosenfield faz, ainda, um resumo das idéias de Kant sobre a República, numa releitura das relaçōes entre a moral e a política e entre o dever e o poder. Baseada na regra da universalização de toda ação, e fundamentada na indagação que escruta o sentido de cada "diç̧ão política", a releitura é elaborada de maneira que permite concluir que os enunciados da açâo sejam válidos independentemente daqueles que os enunciaram.

O autor procede ainda a uma extensa análise dos problemas de nosso tempo, à luz da filosofia politica. No pensamento de Marx, amplamente contemplado neste livro, $o$ papel da razão crítica é bastante salientado. Também a filosofia política de Hegel é considerada, pois, segundo ele, a história tende à realizaçăo da razăo, identificada a efetivaçẫo da liberdade. Da mesma forma que Aristoteles, Hegel tem no cidadão o agente mediador de instâncias que dão forma - e asseguram-nos - aos direitos conquistados. Outros enfoques filosófico-politicos, como de Lévi-Strauss, Hannah Arendt e Hobbes são também descritos com certo pormenor.

O título do livro é a ética na política. Não fica claro, no entanto, que este tenha sido o objetivo do livro, assim como pode-se questionar se o metodo utilizado e o mais adequado para um trabalho sobre ética, tema analisado apenas de passagem. As 90 páginas sã̃o leitura para quem tem afinidade com filosofia política, tema que, na realidade, caracteriza melhor a obra. 